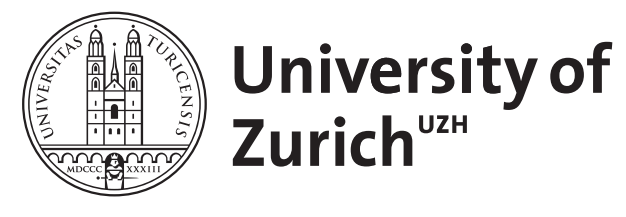

\title{
Personal values in human life
}

\author{
Sagiv, Lilach ; Roccas, Sonia ; Cieciuch, Jan ; Schwartz, Shalom H
}

\begin{abstract}
The construct of values is central to many fields in the social sciences and humanities. The last two decades have seen a growing body of psychological research that investigates the content, structure and consequences of personal values in many cultures. Taking a cross-cultural perspective we review, organize and integrate research on personal values, and point to some of the main findings that this research has yielded. Personal values are subjective in nature, and reflect what people think and state about themselves. Consequently, both researchers and laymen sometimes question the usefulness of personal values in influencing action. Yet, self-reported values predict a large variety of attitudes, preferences and overt behaviours. Individuals act in ways that allow them to express their important values and attain the goals underlying them. Thus, understanding personal values means understanding human behaviour.
\end{abstract}

DOI: https://doi.org/10.1038/s41562-017-0185-3

Posted at the Zurich Open Repository and Archive, University of Zurich

ZORA URL: https://doi.org/10.5167/uzh-169923

Journal Article

Accepted Version

Originally published at:

Sagiv, Lilach; Roccas, Sonia; Cieciuch, Jan; Schwartz, Shalom H (2017). Personal values in human life. Nature Human Behaviour, 1(9):630-639.

DOI: https://doi.org/10.1038/s41562-017-0185-3 


\title{
Personal values in human life
}

\author{
Lilach Sagiv, The Hebrew University of Jerusalem \\ Sonia Roccas, The Open University of Israel
}

Jan Cieciuch, University of Zurich and Cardinal Stefan Wyszyński University in Warsaw and

Shalom H. Schwartz, The Hebrew University of Jerusalem and National University Higher School of Economics

Corresponding author: Lilach Sagiv, The Hebrew University of Jerusalem, email: lilach.sagiv@mail.huji.ac.il

\section{Acknowledgment}

This paper was partly funded by a grant from the Israel Science Foundation (847/14) to the first and second authors, by grants from the Recanati Fund of the School of Business Administration, and from the Mandel Scholion Interdisciplinary Research Center, both at the Hebrew University of Jerusalem, to the first author, and by a grant from The Open University Research Fund of the Open University of Israel to the second author. The work of the third author was supported by the University Research Priority Program Social Networks of the University of Zurich. 


\title{
Personal values in human life
}

\begin{abstract}
The construct of values is central to many fields in the social sciences and humanities. The last two decades have seen a growing body of psychological research that investigates the content, structure and consequences of personal values in many cultures. Taking a cross cultural perspective we review, organize and integrate research on personal values and point to some of the main findings this research has yielded. Personal values are subjective in nature, and reflect what people think and state about themselves. Consequently, researchers and laymen sometimes question their usefulness in influencing action. Yet, selfreported values predict a large variety of attitudes, preferences and overt behaviors. Individuals act in ways that allow them to express their important values and attain the goals underlying them. Thus, understanding personal values means understanding human behavior.
\end{abstract}




\section{Personal values in human life}

Why do some people tend to help others in need while others do not? Why are some people more religious than others? What accounts for individuals' differences in preferences for occupations? The values people hold play a crucial role in such attitudes and behaviors. In this paper we review some of the accumulating research on personal values. Recent research sheds light on the development of values, showing that they are formed through a combination of genetic heritage and the impact of exposure to multiple social environments, such as the family, education system, community and society at large. Although subjective in nature, self-reported values predict a large array of attitudes and preferences. As such, they provide invaluable insight into human behavior.

\section{What Values Are}

Values refer to what is good and worthy ${ }^{1}$. They characterize both individuals and social collectives, such as nations, business organizations, and religious groups. Values of social collectives (often termed cultural values) represent the goals that members of the social collective are encouraged to pursue, and they serve to justify actions taken by collective members and leaders in pursuit of these goals ${ }^{2}$. Values of individuals (often termed personal values) are broad desirable goals that motivate people's action and serve as guiding principles in their lives ${ }^{3} 5$. They affect people's preferences and behavior over time and across situations. In the current review article we focus on personal values. For a brief review of cultural values see Box 1.

Personal values are studied mainly in psychology, although other fields including sociology, management and political science also study them. The construct of personal values was introduced into psychological research by Gordon Allport ${ }^{6}$. For the next 40 years, however, psychology paid relatively little attention to the study of values. Milton Rokeach 
gave new momentum to value research with his proposal that values serve as reference points that people use to formulate attitudes and behaviors ${ }^{4}$. The last three decades have seen a growing body of psychological research on values. Researchers have studied the content, structure, origins and consequences of values in many cultures ${ }^{78951011}$. Personal values are a central content-aspect of the self, distinct from other aspects, such as traits, motives, goals or attitudes ${ }^{12} 1314$.

Personal values are defined as broad, trans-situational, desirable goals that serve as guiding principles in people's lives ${ }^{5}{ }^{4}$. Unpacking this definition points to their unique features, which distinguish them from other central aspects of the self ${ }^{15}{ }^{16}$. We next deconstruct the definition of values. We identify what values share with related constructs such as needs, motives, personality traits, attitudes and specific goals, and how values differ from these constructs.

Values are broad, trans-situational goals. Values are cognitive representations of motivational goals ${ }^{5}$. All values represent goals, but not all goals are values. Values are broad goals that are relevant across a variety of situations. Thus, for example, a person who views independence as an important value in the work context is likely to attribute high importance to this value in other contexts; with friends, family, authority figures, etc. This trans-situational feature distinguishes values from constructs such as attitudes and specific goals, which usually refer to specific actions, objects, or situations.

Values are desirable. Values represent desirable goals; they reflect what people consider important and worthy ${ }^{4}$. People generally view their personal attributes favorably and tend to have positive self-esteem. However, people view their own values as even more desirable than their other personal attributes: They see their values as closer to their ideal self than their personality traits, and wish to modify their values to a lesser extent ${ }^{14}$. 
Values are ordered in hierarchies according to their subjective importance as guiding principles. Each person has a personal hierarchy of value priorities: some values are extremely important, others moderately important, and still others are of some importance. There are some similarities in the value hierarchies of most people. Analyses of self-reports of values revealed that values that express a motivation to care for close others are among the most important values to most people in most societies. In contrast, values that express a motivation to dominate and control others, are among the least important values to most people in most societies ${ }^{17}$. Individuals differ substantially in the importance they attribute to these values, however.

The hierarchical organization of values is a unique feature that distinguishes them from other constructs related to the self concept. It reflects the motivational nature of values: The higher a value in the hierarchy, the more motivated the person is to rely on this value as a guiding principle in life ${ }^{418}$. Consider again the value of independence. A person who attributes high importance to this value is likely to rely on it in making important decisions and choosing actions. Thus, for example, she is likely to seek an occupation that allows some autonomy in choosing how and what to do, to judge severely infractions of people's autonomy, to encourage her children to express independence of thought and action, and to send them to schools that do the same.

\section{The Content and Structure of Values}

The number of possible values is very large. Any dictionary contains hundreds of value terms. Rokeach's value survey ${ }^{4}$ sampled 36 single values (18 termed instrumental and 18 termed terminal values). An important advance in values research was introduced by Schwart $z^{5}$, who theorized that multiple single values express the same broad, underlying motivation. For example, freedom, independence and choosing one's own goals all share the 
motivation for autonomy of thought and action. Thus, long lists of values can be organized into a much shorter list of meaningful types of values.

Schwartz ${ }^{5}$ proposed a theory of universals in the content and structure of personal values. After its presentation in 1992, this theory quickly became prominent in the field ${ }^{911}$. Schwartz suggested that values can be organized according to the motivational goals they express. Analyzing the needs of individuals and the requirements for societal survival, Schwartz $z^{5}$ identified ten motivationally distinct types of values: power, achievement, hedonism, stimulation, self-direction, universalism, benevolence, tradition, conformity, and security. Table 1 (Column 2) presents the definitions of the ten values and provides examples for value-items.

Some of these values are mutually compatible; they reflect goals that can be attained simultaneously through the same actions or attitudes. Other values conflict with each other; actions that promote the attainment of one value are likely to impede the attainment of the other. For example, seeking to challenge existing knowledge by developing a novel theory or research paradigm expresses self-direction values, which express the motivation for autonomy of thought and action. Such behavior also expresses and is compatible with pursuing stimulation values, which reflect the motivation to experience change and novelty and to be daring. Such behavior conflicts, however, with expressing and pursuing conformity values, which reflect the motivation to comply with prevailing norms and expectations and to avoid action that could upset others. The conflicts and compatibilities among the various values determine their structure. Values are structured in a circular continuum, organized according to the motivations they express. Adjacent values express compatible motivations, and opposing values express conflicting motivations (Figure $1^{5}$ ).

Schwart ${ }^{5}$ summarized the circular structure by combining the values into four higher 
order values that form two basic conflicts. The first conflict contrasts self-enhancement with self-transcendence. Self-enhancement values emphasize the pursuit of self-interest by seeking to control people and resources (power) or by exhibiting ambition and socially recognized success (achievement). These values conflict with self-transcendence values that emphasize concern for others, demonstrating care for the welfare of those with whom one has frequent contact (benevolence) or displaying acceptance, tolerance, and concern for all people-even members of outgroups (universalism).

The second conflict contrasts openness to change with conservation. Openness to change values express the motivations for autonomy of thought and action (self-direction) and for novelty and excitement (stimulation). These values conflict with conservation values that express the motivations to preserve the status quo through maintaining traditional beliefs and customs (tradition), to comply with rules and with expectations of others (conformity), and to seek safety and stability (security). Hedonism values share elements of both openness to change and self-enhancement.

The motivational continuum of values can be partitioned in different ways. Many researchers study either the original ten values ${ }^{5}$ or the four higher-order values described above ${ }^{1920}$. However, because the values form a motivational continuum, finer partitions are also possible. Indeed, in a recent refinement of the theory, Schwartz distinguished 19 values on the same continuum ${ }^{21}{ }^{22}$. Column 3 of Table 1 presents the 19 refined values and their definitions.

\section{Cross-Cultural Evidence for the Model of the Content and Structure of Values}

Schwartz's circular model has received support in more than 300 samples from over 80 countries $^{23} 10^{24}$. This consistency in the structure of values (i.e., in the patterns of their interrelations) indicates that the meaning of the value is similar across cultures. That is, when 
people from different cultures consider the importance of a value (e.g., independence), they have in mind a similar idea. Research reveals, however, that the higher the level of social development, the clearer the structure of conflicts and compatibilities is ${ }^{25}$.

In sum, cross-cultural research on personal values reveals commonalities in the meaning of values and some similarity in personal hierarchies of values across cultures. At the same time, this growing body of research indicates substantial variation in the importance attributed to values within and across cultures.

\section{Consequences of Values}

The conceptualization and measurement of values relies most frequently on what people report about themselves. Are value statements merely "cheap talk"? Apparently not. A growing body of research points to the implications of self-reported values for attitudes, preferences, and overt behavior.

\section{Values and Identity}

Values are a core aspect of the self-concept ${ }^{12} 26$. As such, they are related to and reflected in aspects of people's personal and social identity. We illustrate the role of values in identity by discussing their role in two important aspects of people's personal and social lives-religiosity and career choice. We choose these two domains because both are relevant to most people, entail aspects of both personal and social identity, and require explicit and implicit decisions throughout the life course. These two examples provide insights into how values shape one's identity and the role values play in making us who we are.

Values and religiosity. The religious groups with which individuals affiliate and the extent of their religiosity are important aspects of their personal and social identity 2728 . People feel that religiosity often defines who they are and influences their beliefs, attitudes and behaviors. Researchers have long been interested in understanding differences 
between religious and non-religious individuals, and between adherents of different religions. The research relating values to religiosity provides insights into the ways in which those who identify themselves as religious differ from others.

In one of the earliest works in this area, Schwartz and Huismans ${ }^{29}$ examined the motivational meaning of religiosity by investigating its correlations with values. They reasoned that religiosity is consistent with the goals of conservation values, particularly tradition, due to the focus of these values on submitting to transcendental authorities and on reducing uncertainty by emphasizing self-restriction, order, and resistance to change. In contrast, religiosity is inconsistent with openness to change values because these values promote autonomy of thought and action, and embrace novelty and change. Hedonism is particularly incompatible with religiosity because a primary function of all religions is to temper self-indulgence and gratification of material desires.

This reasoning led Schwartz and Huismans ${ }^{29}$ to hypothesize that values relate similarly to religiosity regardless of the religion in question. Their study supported this hypothesis, as did numerous subsequent studies that examined samples from a large variety of religions (e.g. Roman Catholics ${ }^{30} 31$; Anglicans ${ }^{32}$; Jews ${ }^{33}$ 13; Muslims $^{34}$ 35; Buddhists $^{36}$ ).

The pattern of correlations between values and religiosity was strikingly consistent across monotheistic religions: religiosity correlated positively with emphasizing conservation values, most strongly tradition, and negatively with emphasizing values of openness to change, self-direction, stimulation and hedonism. A meta-analysis of the findings of 21 samples in 15 countries revealed average correlations that ranged from .49 (with tradition) to -.34 (with hedonism ${ }^{37}$; see also Roccas \& Elster ${ }^{38}$ for a recent review). Findings further indicate that values are correlated more strongly with religiosity than with the affiliation with a specific religion ${ }^{39}$. In sum, religious individuals differ from non-religious ones in similar ways 
across religious groups. This research thus sheds light on the motivational meaning of religiosity.

Values and career choice. The work domain is another central aspect of life. Most individuals are heavily invested in their workplace; physically, cognitively and emotionally, and their occupation is an important aspect of their identity. People with different occupations are characterized by different value priorities. Thus, for example, managers, bankers and financial advisors emphasize power and achievement values more than individuals in other occupations, psychologists and social workers emphasize benevolence and universalism more than others, and secretaries and bookkeepers emphasize security, conformity and tradition more than others ${ }^{40}$. These value profiles are not arbitrary; rather, the occupations facilitate attainment of the goals that their members consider to be important. Value congruency, or fit, between people's values and their work environment is related to work satisfaction (see a review in Kristof-Brown, Zimmerman, \& Johnson ${ }^{41}$ ).

What is the source of this value congruency? Do people choose occupations that are compatible with their values? Or do their values change overtime so that they match their occupation and workplace? Melvin Kohn and colleagues have examined the effects of the different characteristics of workplaces on values. In longitudinal analyses over decades, they found that the importance people attribute to self-direction versus conformity values increases to the extent to which their work is characterized by low supervision and entails complex and varied tasks. These effects have transgenerational implications because the characteristics of the occupational environment of the parents affect the values they wish to instill in their children ${ }^{42} 4344$. These effects are robust, and can be found even in societies undergoing social change ${ }^{45}$.

The work of Kohn and colleagues focused on the effects of environmental complexity 
on values. Environmental complexity, however, does not fully explain the value differences between people in different occupations because there are value differences even between people in occupations that are similar in their complexity. Moreover, there are value differences between people in different occupations, not only in self-direction and conformity values, but also in self enhancement and self transcendence values. These value differences cannot be explained by work complexity.

Studies that compared students from different academic departments at the beginning and end of their university studies, provide evidence for a value-based self-selection process ${ }^{46}$ 4748 . The findings reveal that value differences between students enrolled in different departments are already present at the very beginning of the first year of study. This suggests that individuals rely on their values, at least in part, when choosing the occupation or profession for which they wish to prepare. In contrast, there is only minimal evidence for the impact of socialization processes: students' values hardly changed during the years they spent at the university ${ }^{46}{ }^{47}$. Further research is required to investigate potential effects on values of long-term organizational socialization ${ }^{49}$.

\section{Values and Behavior toward Others}

Values influence individuals' thoughts, attitudes, choices and decisions. Their impact is not limited to people's identity, however, they also affect how individuals act toward others. One domain that has attracted attention is the impact of values on pro-social behavior actions intended to protect or to enhance the welfare of others. In the review below, we distinguish between studies of attitudes and behavior toward close others, that is, people with whom one has direct contact, and studies of attitudes and behavior toward people with whom one is less likely to have a direct contact, such as members of outgroups.

Values and close others. Much of everyday life involves interaction with others. During 
such interaction, people decide how much to invest in the welfare of the others by providing tangible or intangible resources such as time, advice, or money. Helping others sometimes comes at the expense of promoting one's own interest. Nonetheless, some people choose to contribute, cooperate and help others rather than compete. Which values predict whether a person is likely to help others or not? Many studies have addressed this question.

Benevolence values (one of the self-transcendence values) express the motivation to care for close others. Most people report that these values are very important to them ${ }^{17}$. Nonetheless, people differ in the importance they attribute to benevolence values, and the more important these values are, the more one is likely to help others. Studying the relationships between values and daily behaviors, Bardi and Schwartz ${ }^{50}$ found that the importance of benevolence values correlated positively with the likelihood of engaging in helpful acts such as lending things to neighbours or keeping promises (as reported by themselves and by close others). A recent research in four countries (Poland, Italy, Russia and the USA) revealed similar findings ${ }^{51}$. Along the same lines, managers who emphasized selftranscendence values were evaluated by their employees as behaving more altruistically than managers who emphasized self-enhancement values ${ }^{52}$.

Emphasizing benevolence values correlated with various forms of everyday kindness ${ }^{53}$. The magnitude of the correlations is typically medium-small to medium-large. People who emphasize these values were more likely to volunteer to help others ${ }^{54}{ }^{55}$, to donate money to a social cause ${ }^{56}$, or to emphasize a volunteering identity over time ${ }^{12}$. Maio and Olson ${ }^{57}$ showed that when participants were directed to think about the benefit for others, emphasizing benevolence values predicted willingness to donate to cancer research above and beyond the impact of attitudes and social norms. In a recent study conducted in four cultures, participants who reported their values as part of a survey were later re-contacted and asked to complete 
some of the survey again, because the experimenter has allegedly lost some of their data. In Turkey, self-transcendence (vs. self-enhancement) values positively predicted the helpful behavior (i.e., re-completing the survey). In the other three cultures (Germany, Israel \& Scotland) the findings had the same pattern, but they were weak and not statistically significant $^{58}$.

Researchers have studied not only the associations between values and pro-social action but also the causal influence of self-transcendence values on such behavior. Researchers primed participants in these studies with benevolence values - for example, by having them read benevolence-related words (in the primed benevolence condition) versus unrelated words (in the control condition). Then, after the experiment was allegedly over, they were asked to volunteer to help the experimenter with another study even though he could not pay them (Maio et al. ${ }^{54}$ in the UK), and whether they would be willing to donate money to Amnesty (Verplanken and Holland ${ }^{56}$ in the Netherlands). In both studies, participants who were primed with benevolence words acted more altruistically than participants in the other conditions. In another study, conducted in Israel, the importance of benevolence values was primed more explicitly: The participants in the experimental condition engaged in a self-persuasion intervention designed to increase the importance of benevolence values. Following the intervention, they were asked - in an allegedly unrelated part of a questionnaire - to volunteer to help social organizations. Those in the benevolence intervention condition were twice as likely to volunteer as those in the control condition ${ }^{55}$.

The effects of values on behavior were also studied in situations involving socialdilemmas. Social dilemmas confront people with the choice of cooperating with others, at some cost to themselves, or competing, at the expense. Researchers developed socialdilemma games (also termed strategic, or economic games) in order to make the incentives 
and costs attached to each decision clear. These games allow researchers to investigate overt behavior that simulates real-life behavior. Values are likely to predict behavior in such games to the extent that each choice in the game leads to attaining a distinct motivational goal.

Two dilemma games designed to investigate cooperation versus competition illustrate the impact of values ${ }^{59}$. Participants were asked to decide whether to cooperate by contributing an amount of money to their partner (Study 1, conducted in Israel) or to their group (Study 2, conducted in the US), or to compete (i.e., keep the money for themselves). In both games, competing was the economically-wise decision, resulting in receiving more money, regardless of the actions of other participants in the game. The researchers reasoned that competing would be compatible with emphasizing power values that express the motivation for power, dominance and control over others, whereas cooperating (i.e., contributing money) would be compatible with self-transcendence (in particular benevolence) values. The findings in both studies were consistent with the expected pattern.

Decisions in social dilemma games have also been related to Social Value Orientations (SVO), which are preferences for specific types of resource allocations in interdependent interactions ${ }^{606162}$. We did not include these studies in the present review because social value orientations differ from values in that they are inferred from specific patterns of preference, or choice. Thus, they are narrower than values and contextualized; they are more similar to specific goals than to values ${ }^{59}$.

Self-transcendence and power values may not always predict behavior in socialdilemma games, however. Lönnqvist and colleagues ${ }^{63}$ suggest that some behaviors are value expressive - they are compatible with one motivation, and are therefore likely to be consistently related to the values that express this motivation. Other behaviors are value 
ambivalent; they can serve more than one motivational goal. In such cases people, with different value priorities may adopt the same behavior. This leads to inconsistent relationships between values and behavior. Lönnqvist found support for this distinction in analyses of behavior in different types of social dilemmas in samples from Germany, Finland and Israel. Values consistently predicted cooperative behaviors that they classified as value expressive (correlations were small to medium). In contrast, the impact of values was inconsistent or weak for behaviors that they classified as value ambivalent.

Values and distant others. Much of the research examining the relations of values to action toward distant others, examines tolerance toward people who differ from societal norms in their socio-demographic characteristics (e.g., ethnicity, religion) or in their personal attitudes and preferences. Analyzing the motivations underlying tolerance and intolerance, Sagiv and Schwartz ${ }^{64}$ reasoned that universalism values (a self-transcendence value), which express concern for the welfare of all others, including those whose life-style differs from one's own, foster tolerance toward others. Tolerance is also closely related to the key goals of openness to change values, because contact with people who are not members of the dominant society affords opportunities for novelty and excitement and independence from following the life-style of ones' in-group.

In contrast, tolerance conflicts with the emphasis of conservation values on maintaining the status quo in social and cultural arrangements. These values promote obedience to prevailing norms and expectations (conformity values) and avoidance of anything new and unfamiliar (tradition values). Accepting or mingling with people who deviate from the dominant culture conflicts with attaining the goals of conservation values. Finally, tolerance may be compatible or conflicting with the goals of self-enhancement values, depending on the social context. These values emphasize self-interest; tolerance toward people who 
deviate from the dominant culture may promote self-interest in some cases, but hinder it in others.

Extensive research supports this analysis. Attributing high importance to universalism and openness-to-change values, and low importance to Conservation values, has been found to relate to tolerance toward various minority groups by dominant group members in several cultures. This pattern emerged, for example, in a study of willingness for contact with members of the Arab minority among Israeli Jews ${ }^{64}$ and willingness of Israeli and Jordanian businesspeople for contact with each other ${ }^{65}$. A similar pattern emerged in studies conducted in Europe on attitudes toward immigration: Attributing high importance to universalism values related positively and attributing high importance to conservation values (tradition, conformity and security) related negatively to favorable attitudes toward immigration 666768 . Values predicted tolerant attitudes above and beyond the impact of socio-demographic variables, and their impact was typically stronger than that of other individual-level variables.

This pattern holds not only for tolerance toward ethnic outgroups but also for tolerance toward other minority groups. Studies of attitudes toward homosexuality in Europe showed the same pattern. The more important openness to change and universalism values to people, and the less important conservation and power values, the more positive their views of homosexuality 697071 . Interestingly, the associations of openness to change and conservation values with attitudes toward homosexuality were especially strong in countries with less progressive laws regarding homosexuality. That is, when the social context was less tolerant, the personal values related to group identity (independence from the group or dependence on the group) had a stronger effect on tolerance. Surveys of attitudes toward a variety of minority groups (e.g., sexism, anti-Semitism, anti-foreigner attitudes, anti-Muslim attitudes) also revealed that universalism and conservation values relate directly to tolerance of those 
who differ from the dominant group in society ${ }^{72}$.

Values also relate to attitudes toward members of outgroups in indirect ways. For example, values shape reactions to members of minority groups by affecting how people react to diversity in society. In an experimental study conducted in Israel, researchers manipulated the salience of the heterogeneity or homogeneity of the religious ingroup (Jews) by showing participants photographs of Jewish weddings. In the homogeneity condition, the pictures depicted prototypical Jewish-Israeli wedding ceremonies. In the heterogeneity condition, the pictures depicted non-prototypical weddings, including a wedding of two men and a wedding of a man and a woman dressed as Ultra-Orthodox Jews. Participants then reported their willingness for contact with a mixed faith couple (a Jewish woman married to a Muslim man).

Conservation values moderated the reactions to the photographs. Participants who attributed high importance to conservation values expressed more tolerance in the homogeneity than in the heterogeneity condition. In contrast, those who attributed low importance to conservation values expressed more tolerance in the heterogeneity condition or were unaffected by the type of pictures. These findings replicated in two other experiments that exposed the participants to other sets of photographs and other targets of tolerance ${ }^{73}$.

The moderating impact of values on reactions to heterogeneity was conceptually replicated in a field study in Israel. The researchers investigated the relationship of the diversity of individuals' networks to tolerance. The relative importance of conservation and openness to change values moderated the effects of network diversity on tolerance ${ }^{74}$. Together, these studies indicate the robustness of the finding, pointing to one of the complex ways in which values affect people's actions and reactions. 


\section{The Origins of Values}

Values play an important role in psychological functioning in many areas of life. But where do people's different value priorities come from and how are they shaped? In order to answer these questions, we differentiate between the phylogenetic and ontogenetic perspectives ${ }^{75}$. The phylogenetic perspective explains why there is a relatively similar, pancultural hierarchy of values across societies. The ontogenetic perspective examines the processes through which individuals' hierarchies of values are formed.

The phylogenetic perspective. The phylogenetic perspective suggests that the crucial role of groups for human survival is the main driving factor in the development of values. Groups, by their very nature, require their members to communicate about and coordinate their interests, needs, and behaviors in order to enhance their chances for survival. Through trial and error, group members develop shared ways of representing their needs and communicating about them in acceptable ways with their fellow group members. Values are representations of the socially desirable goals people seek. They are central to the shared meaning systems that develop as group members seek to coordinate their goal-seeking activities. Thus, values are a core element of culture ${ }^{76}$.

According to the phylogenetic perspective, the similarity of the hierarchy of values found in most cultures is not accidental. It reflects the conditions needed for group survival and welfare. Because groups are complex systems, the analysis of the conditions essential for groups to flourish can be described in terms of cybernetics ${ }^{77}$. Complex systems need to develop the capacity both (a) for maintaining the stability of relations, resources, and ways of dealing with internal and external dangers, and (b) for plasticity and adaptation to changing environmental conditions. The hierarchy of values that groups develop supports and promotes these capacities. 
Empirical research shows wide-spread pan-cultural agreement on the most important values. In their assessment of value hierarchies in 63 societies, Schwartz and Bardi ${ }^{17}$ found that the two values that were almost always at the top of the hierarchy were benevolence and self-direction. The high priority of benevolence is likely due to its importance for maintaining in-group cooperation and solidarity, and thereby contributing to the stability of social relations. The high priority of self-direction is likely due to its importance for encouraging and supporting plasticity by motivating independent initiatives and novel ideas and solutions. Because groups require both stability and plasticity in order to survive, these same two values are the most important in most cultures that have been studied.

Although there is wide-spread pan-cultural agreement at the country level, research and everyday experience tell us that individuals differ substantially in what they consider important. The ontogenetic perspective seeks to explain the inter-individual diversity of value preferences.

The ontogenetic perspective. There is growing evidence that value hierarchies are shaped quite early. The circular structure of values is found among 5-12 year olds ${ }^{78} 79$. This indicates that children at age 5 already distinguish between the different values and that their value hierarchies reflect the conflicts and compatibilities between the values. However, the importance of specific values changes over time as part of psychosocial development during childhood and adolescence ${ }^{80}$. Individuals' hierarchies of values stabilize during adolescence and change little during adulthood ${ }^{82}$, as a relatively stable core element of personal identity ${ }^{82}$. Individual differences in value priorities derive from both biologically based individual temperament/personality and social and cultural influences ${ }^{80}$. Several studies provide estimates of the genetic bases of value preferences. Uzefovsky, Döring and Knafo-Noam ${ }^{83}$ estimated that genetics accounts for $29 \%-47 \%$ of preferences for the higher order values, 
except openness, among 7 year-old children. Other estimates are $28 \%-55 \%$ for the dimensions of openness vs. conservation and of self-enhancement vs. self-transcendence among 7-11 year-olds ${ }^{84}$, and $11 \%-38 \%$ for all values except achievement, among 18-33 yearolds ${ }^{85}$. These levels of heritability are only slightly lower than the approximately $40 \%$ estimated for personality traits ${ }^{86}$.

The particular social and cultural surroundings into which a child is born and grows is the other critical influence on value priorities. Parents and other primary caregivers are the main transmitters of values, directly or indirectly ${ }^{87}$. Families are powerful vehicles of value socialization. Parents generally desire their children to have values similar to their own and, indeed, there is high congruence between the value hierarchies of parents and those of their children ${ }^{88}{ }^{89}$. Value transmission within a family involves an active process in which children perceive the values of their parents more or less accurately and choose to adopt or reject the values they perceive ${ }^{90} 91$. The closer children feel to their parents the more similar they perceive their values to $b^{92}$. Yet, much of the value similarity between parents and children is due not to direct value transmission from parents to children but to the environment and to the culture they share. For example, parents and children share the same socio-economic status and both are exposed to the same cultural institutions (see Hitlin and Piliavin ${ }^{7}$ for a review).

As children enter adolescence, they gain increased influence over the environment to which they are exposed. They are freer to choose their friends and shape a social network ${ }^{93}$. Adolescents become more and more embedded in social institutions outside the family where they may acquire values that contribute to their unique value hierarchies.

In sum, research has revealed many factors effecting the development of values, ranging from genetic factors, to the immediate social environment, to the impact of societal 
institutions such as family and school, to the impact of societal culture. To date, no unifying model has been proposed that integrates these factors and identifies their relative importance.

\section{Stability and Change of Values}

The importance of values leads researchers to investigate their stability and change. Can people change their values? Laypeople as well as researchers often assume that people can change their values quite easily, especially compared with other personality attributes such as traits. They assume that people can simply change their minds about their value priorities because values are subjective and reflect what they themselves consider important. Contrary to this assumption, however, when adults were asked whether they could change their values should they want to, they said it would be very difficult, even more difficult than changing their traits ${ }^{14}$. Attempting to explain this finding, Roccas and colleagues ${ }^{14}$ reasoned that changing one's values entails altering the very core of one's identity; individuals therefore perceive such change as difficult and unlikely.

Numerous studies reveal that values are relatively stable over time (see a review in Bardi and Goodwin $\left.{ }^{94}\right)$. Longitudinal studies revealed high test-retest stability of values in the short term (e.g., one month, around .70-.90). Stability remains high after two, three and even

eight years (.50 to .70 959620 ). Considering that contextual factors and even random noise may affect individuals' reports of their value priorities, the extent of consistency in values across time is remarkable.

Values do sometimes change, however. Research indicates that major life-transitions can produce substantial value change. Migrating to a culture that emphasizes values different from those emphasized in one's culture of origin is a notable example. A study of immigrants from Russia to Finland ${ }^{97}$ revealed changes in the personal values of the 
immigrants. After about 19 months in Finland, the importance of universalism and security increased, and the importance of power and achievement decreased. Another study, focusing on Polish immigrants to the UK, indicated that their values were similar to those of individuals in the UK even before migrating (i.e., there was evidence for value-based selfselection). However, after 18-21 months in the UK there was also some evidence for value change: Immigrants' self-direction and power values changed to become similar to those of people in the $\mathrm{UK}^{47}$. Importantly, in both studies, the correlations between personal values before and after the migration, was high (Lönnqvist et al. ${ }^{97}: .37-.63 ; .68-1$ after correcting for internal reliability; Bardi et al $\left.{ }^{47}: .50-.69\right)$.

Is it possible to deliberately change the value priorities of another person? Social institutions often seek to shape the values of their members ${ }^{55}$. Apparently, however, this is not a simple task. Studies indicate, for example, that university training and socialization change values minimally, if at all 46474 . Some researchers have described intervention programs that trigger value change, including self-confrontation ${ }^{49854}$ and self-persuasion ${ }^{55}$ interventions (see a review in Roccas, Sagiv and Navon ${ }^{99}$ ).

Research on value change further shows that the structure of within-person values change was similar to the prototypical structure of values (see Figure 1): When the importance of a value increased, the importance of its opposing value tended to decrease ${ }^{100}$ 97. This finding is consistent with the view that values form a consistent meaning system. A change in one aspect of the system is accompanied by consistent changes in other parts of the system.

\section{Concluding remarks}

Values are a core aspect of people's identity and they affect their attitudes and behaviors. In this review we have drawn from research conducted in many sub-disciplines 
of psychology: personality, social, developmental, occupational, organizational and crosscultural. Together, this research shows that values can serve as a unifying construct that bridges sub-disciplines of psychology. Studying values provides insight into the ways people are motivated by stable goals that they wish to attain. Values, due to their abstract nature, predict behavior across different social contexts and the same value can predict very different behaviors. Thus for example, conservation values predict both religiosity and (in) tolerance toward others. Moreover, values form an integrated meaning system. Therefore studying a behavior while taking into account the full spectrum of human values allows for a deep understanding of the multiple motivations that direct a single behavior.

We exemplified the research on the consequences of values by focusing on identity and on behavior directed to others. Research on the consequences of values not only helps predict behavior, it contributes to understanding the motivation underlying behaviors and the complex interplay between personality and the social context.

To-date, much is known about the content of the values-behavior relationships. More research is needed, however, that to investigate the processes through which values are translated into behavior. Some of the studies reviewed above pointed to such paths of influence. Future research could enrich this line of work which could be instrumental to organizational and social attempts to motivate action.

In contrast to the numerous studies investigating the consequences of values, much less is known about the origin of values. Discussing the phylogenetic and ontogenetic perspectives, we reviewed recent theorizing and evidence on this important issue. These newly developments in value research suggest that personal values are formed through a combination of genetic heritage and the impact of exposure to multiple social environments, including family, school, community and society at large. An intriguing 
question future research is how values are grounded in the neuro-biological system. Combined together, interdisciplinary research will enable a better understanding of the complex interplay between these factors in forming personal value hierarchies.

\section{Competing interests}

The authors declare no competing interests. 


\section{References}

1. Williams, R. M. (1970). American society: A sociological interpretation (p. 58). New York, NY: Knopf.

2. Schwartz, S. H. (1999). A theory of cultural values and some implications for work. Applied Psychology: An International Review, 48(1), 23-47.

3. Kluckhohn, C. (1951). Values and value-orientations in the theory of action: An exploration in definition and classification. In T. Parsons \& E. Shils (Eds.), Toward a general theory of action (pp. 388-433). Cambridge, MA: Harvard University Press.

4. Rokeach, M. (1973). The nature of human values. New York, NY: Free Press.

5. Schwartz, S. H. (1992). Universals in the content and structure of values: Theoretical advances and empirical tests in 20 countries. In M. Zanna (Ed.), Advances in experimental social psychology (Vol. 25, pp. 1-65). London, UK: Academic Press.

6. Allport, G. W., \& Vernon, P. (1931). A test for personal values. The Journal of Abnormal and Social Psychology, 26(3), 231-248.

7. Hitlin, S., \& Piliavin, J. A. (2004). Values: Reviving a dormant concept. Annual Review of Sociology, 30, 359-393.

8. Maio, G. R. (2010). Mental representations of social values. Advances in Experimental Social Psychology, 42, 1-43.

9. Rohan, M. J. (2000). A rose by any name? The values construct. Personality and Social Psychology Review, 4(3), 255-277.

10. Schwartz, S. H. (2015). Basic individual values: Sources and consequences. In D. Sander and T. Brosch (Eds.), Handbook of value (pp. 63-84). Oxford, UK: Oxford University Press.

11. Knafo, A., Roccas, S., \& Sagiv, L. (2011). The value of values in cross cultural 
research: A special issue in honor of Shalom Schwartz. Journal of Cross-Cultural Psychology, 42(2), 178-185.

12. Hitlin, S. (2003). Values as the core of personal identity: Drawing links between two theories of self. Social Psychology Quarterly, 66(2), 118-137.

13. Roccas, S., Sagiv, L., Schwartz, S. H., \& Knafo, A. (2002). The Big Five personality factors and personal values. Personality and Social Psychology Bulletin, 28(6), 789-801.

14. Roccas, S., Sagiv, L., Oppenheim, S., Elster, A., \& Gal, A. (2014). Integrating content and structure aspects of the self: Traits, values, and self-improvement. Journal of Personality, 82(2), 144-157.

15. Roccas, S., \& Sagiv, L. (2010). Personal values and behavior: Taking the cultural context into account. Social and Personality Psychology Compass, 4(1), 30-41.

16. Sagiv, L., \& Roccas, S. (forthcoming). What values are and what they are not. In S. Roccas \& L. Sagiv (Eds.), Values and behavior: Taking a cross-cultural perspective. Springer.

17. Schwartz, S. H., \& Bardi, A. (2001). Value hierarchies across cultures: Taking a similarities perspective. Journal of Cross-Cultural Psychology, 32(3), 268-290.

18. Schwartz, S. H. (1996). Value priorities and behavior: Applying a theory of integrated value systems. In C. Seligman, J. M. Olson, \& M. P. Zanna (Eds.), The Ontario symposium: The psychology of values (Vol. 8, pp. 1-24). Mahwah, NJ: Lawrence Erlbaum Associates, Inc.

19. Benish-Weisman, M. (2015). The interplay between values and aggression in adolescence: A longitudinal study. Developmental Psychology, 51(5), 677-687.

20. Vecchione, M., Döring, A. K., Alessandri, G., Marsicano, G., \& Bardi, A. (2016). Reciprocal relations across time between basic values and value-expressive behaviors: A longitudinal study among children. Social Development, 25(3), 528- 
547.

21. Schwartz, S. H., Cieciuch, J., Vecchione, M., Davidov, E., Fischer, R., Beierlein, C., . . . Konty, M. (2012). Refining the theory of basic individual values. Journal of Personality and Social Psychology, 103(4), 663-688.

22. Schwartz, S. H., Cieciuch, J., Vecchione, M., Torres, C., Dirilen-Gumus, O., \& Butenko, T. (2016). Value tradeoffs propel and inhibit behavior: Validating the 19 refined values in four countries. European Journal of Social Psychology.

23. Davidov, E., Schmidt, P., \& Schwartz, S. H. (2008). Bringing values back in: The adequacy of the European Social Survey to measure values in 20 countries. Public Opinion Quarterly, 72(3), 420-445.

24. Schwartz, S. H., \& Rubel, T. (2005). Sex differences in value priorities: Cross-cultural and multimethod studies. Journal of Personality and Social Psychology, 89(6), 10101028.

25. Fontaine, J. R. J., Poortinga, Y. H., Delbeke, L., \& Schwartz, S. H. (2008). Structural equivalence of the values domain across cultures: Distinguishing sampling fluctuations from meaningful variation. Journal of Cross-Cultural Psychology, 39(4), 345-365.

26. Miles, A. (2015). The (re) genesis of values examining the importance of values for action. American Sociological Review, 80(4), 680-704.

27. Hogg, M. A., Adelman, J. R., \& Blagg, R. D. (2010). Religion in the face of uncertainty: Uncertainty-identity theory of religiousness and religious extremism. Personality and Social Psychology Review, 14, 72-83.

28. Ysseldyk, R., Matheson, K., \& Anisman, H. (2010). Religiosity as identity: Toward an understanding of religion from a social identity perspective. Personality and Social 
Psychology Review, 14, 60-71.

29. Schwartz, S. H., \& Huismans, S. (1995). Value priorities and religiosity in four Western religions. Social Psychology Quarterly, 58(2), 88-107.

30. Bilsky, W., \& Peters, M. (1999). Estructura de los valores y la religiosidad: Una investigacion comparada realizada en Mexico. Revista Mexicana de Psicologia, 16, $77-88$.

31. Fontaine, J. R. J., Luyten, P., \& Corveleyn, J. (2000). Tell me what you believe and I'll tell you what you want: Empirical evidence for discriminating value patterns of five types of religiosity. International Journal for the Psychology of Religion, 10, 65-84.

32. Pepper, M., Jackson, T., \& Uzzell, D. (2010). A study of multidimensional religion constructs and values in the United Kingdom. Journal for the Social Scientific Study of Religion, 49, 127-146.

33. Saroglou, V., \& Hanique, B. (2006). Jewish identity, values, and religion in a globalized world: A study of late adolescents. Identity: An International Journal of Theory and Research, 6, 231-249.

34. Saroglou, V., \& Galand, P. (2004). Identities, values, and religion: A study among Muslim, other immigrant, and native Belgian young adults after the $9 / 11$ attacks. Identity: An International Journal of Theory and Research, 4, 97-132.

35. Kusdil, M. E., \& Kagitcibasi, C. (2000). Tuerk oegretmenlerin deger yoenelimleri ve Schwartz deger kurami [Value orientations of Turkish teachers and Schwartz's theory of values]. Turk Psikoloji Dergisi, 15, 59-80.

36. Saroglou, V., \& Dupuis, J. (2006). Being Buddhist in Western Europe: Cognitive needs, prosocial character, and values. International Journal for the Psychology of Religion, 16, 163-179. 
37. Saroglou, V., Delpierre, V., \& Dernelle, R. (2004). Values and religiosity: A metaanalysis of studies using Schwartz's model. Personality and Individual Differences, 37(4), 721-734.

38. Roccas, S., \& Elster, A. (2014). Values and religiosity. In V. Saroglou (Ed.), Religion, personality, and social behavior (pp. 193-212). New York, NY: Psychology Press.

39. Longest, K. C., Hitlin, S., \& Vaisey, S. (2013). Position and disposition: The contextual development of human values. Social Forces, 91(4), 1499-1528.

40. Knafo, A., \& Sagiv, L. (2004). Values and work environment: Mapping 32 occupations. European Journal of Psychology of Education, 19(3), 255-273.

41. Kristof-Brown, A. L., Zimmerman, R. D., \& Johnson, E. C. (2005). Consequences of individual's fit at work: A meta-analysis of person-job, person-organization, persongroup, and person-supervisor fit. Personnel Psychology, 58(2), 281-342.

42. Kohn, M. L. (1963). Social class and parent-child relationships: An interpretation. American Journal of Sociology, 68(4), 471-480.

43. Kohn, M. L., \& Slomczynski, K. M. (1993). Social structure and self-direction: A comparative analysis of the United States and Poland. Oxford, UK: Blackwell.

44. Kohn, M. L., \& Schooler, C. (1983). Work and personality: An inquiry into the impact of social stratification. Norwood, NJ: Ablex.

45. Kohn, M. L., Zaborowski, W., Janicka, K., Mach, B. W., Khmelko, V., Slomczynski, K. M., . . Podobnik, B. (2000). Complexity of activities and personality under conditions of radical social change: A comparative analysis of Poland and Ukraine. Social Psychology Quarterly, 63(3), 187-207.

46. Arieli, S., Sagiv, L., \& Cohen-Shalem, E. (2016). Values in business schools: The role of self-selection and socialization. Academy of Management Learning \& Education, 
15(3), 493-507.

47. Bardi, A., Buchanan, K. E., Goodwin, R., Slabu, L., \& Robinson, M. P. (2014). Value stability and change during self-chosen life transitions: Self-selection vs. socialization effects. Journal of Personality and Social Psychology, 106(1), 131-147.

48. Gandal, N., Roccas, S., Sagiv, L., \& Wrzesniewski, A. (2005). Personal value priorities of economists. Human Relations, 58(10), 1227-1252.

49. Chatman, J. A. (1991). Matching people and organizations: Selection and socialization in public accounting firms. Administrative Science Quarterly, 36(3), 459-484.

50. Bardi, A., \& Schwartz, S. H. (2003). Values and behavior: Strength and structure of relations. Personality and Social Psychology Bulletin, 29(10), 1207-1220.

51. Schwartz, S. H., Cieciuch, J., Vecchione, M., Torres, C., Dirilem-Gumus, O., \& Butenko, T. (2017). Value tradeoffs and behavior in four countries: Validating 19 refined values. European Journal of Social Psychology, 47

52. Sosik, J. J., Jung, D. I., \& Dinger, S. L. (2009). Values in authentic action: Examining the roots and rewards of altruistic leadership. Group \& Organization Management, 34(4), 395- 431.

53. Sanderson, R., \& McQuilkin, J. (forthcoming). Many kinds of kindness: The relationship between values and pro-social behavior. In S. Roccas \& L. Sagiv, (Eds.), Values and behavior: Taking a cross-cultural perspective. Springer.

54. Maio, G. R., Pakizeh, A., Cheung, W. Y., \& Rees, K. J. (2009). Changing, priming, and acting on values: Effects via motivational relations in a circular model. Journal of Personality and Social Psychology, 97(4), 699-715.

55. Arieli, S., Grant, A. M., \& Sagiv, L. (2014). Convincing yourself to care about others: 
An intervention for enhancing benevolence values. Journal of Personality, 82(1),

$15-24$.

56. Verplanken, B., \& Holland, R. W. (2002). Motivated decision making: Effects of activation and self-centrality of values on choices and behavior. Journal of Personality and Social Psychology, 82(3), 434-447.

57. Maio, G. R., \& Olson, J. M. (1995). Relations between values, attitudes, and behavioral intentions: The moderating role of attitude function. Journal of Experimental Social Psychology, 31(3), 266-285.

58. Daniel, E., Bilgin, A. S., Brezina, I., Strohmeier C. E., \& Vainre, M. (2015). Values and helping behavior: A study in four cultures. International Journal of Psychology, 50(3), 186-192.

59. Sagiv, L., Sverdlik, N., \& Schwarz, N. (2011). To compete or to cooperate? Values' impact on perception and action in social dilemma games. European Journal of Social Psychology, 41(1), 64-77.

60. Samuelson, C. D. (1993). A multiattribute evaluation approach to structural change in resource dilemmas. Organizational Behavior and Human Decision Processes, 55(2), 298-324.

61. Simpson, B., \& Willer, R. (2008). Altruism and indirect reciprocity: The interaction of person and situation in prosocial behavior. Social Psychology Quarterly, 71(1), 37-52.

62. Van Lange, P. A. (1999). The pursuit of joint outcomes and equality in outcomes: An integrative model of social value orientation. Journal of Personality and Social Psychology, 77(2), 337-349.

63. Lönnqvist, J. E., Verkasalo, M., Wichardt, P. C., \& Walkowitz, G. (2013). Personal values and prosocial behaviour in strategic interactions: Distinguishing value- 
expressive from value-ambivalent behaviours. European Journal of Social Psychology, 43(6), 554-569.

64. Sagiv, L., \& Schwartz, S. H. (1995). Value priorities and readiness for out-group social contact. Journal of Personality and Social Psychology, 69(3), 437-448.

65. Sagiv, L., Makhamra, M., \& Kluger, A. N. (2004, January). Direct and indirect influence of culture on managers' willingness for cross cultural cooperation. Third Annual Meeting of the Society of Personality and Social Psychology, Austin, Texas, US.

66. Davidov, E., \& Meuleman, B. (2012). Explaining attitudes towards immigration policies in European countries: The role of human values. Journal of Ethnic and Migration Studies, 38(5), 757-775.

67. Davidov, E., Meuleman, B., Billiet, J., \& Schmidt, P. (2008). Values and support for immigration: A cross-country comparison. European Sociological Review, 24(5), 583-599.

68. Davidov, E., Meulemann, B., Schwartz, S. H., \& Schmidt, P. (2014). Individual values, cultural embeddedness, and anti-immigration sentiments: Explaining differences in the effect of values on attitudes toward immigration across Europe. KZfSS Kölner Zeitschrift für Soziologie und Sozialpsychologie, 66, 263-285.

69. Kuntz, A., Davidov, E., Schwartz, S. H., \& Schmidt, P. (2015). Human values, legal regulation, and approval of homosexuality in Europe: A cross-country comparison. European Journal of Social Psychology, 45(1), 120-134.

70. Donaldson, C. D., Handren, L. M., \& Lac, A. (2017). Applying multilevel modeling to understand individual and cross-cultural variations in attitudes toward homosexual people across 28 European countries. Journal of Cross-Cultural Psychology, 48(1), 93-112. 
71. Licciardello, O., Castiglione, C., \& Rampullo, A. (2011). Intergroup contact, value system and the representation of homosexuality. Procedia-Social and Behavioral Sciences, 30, 1467-1471.

72. Beierlein, C., Kuntz, A., \& Davidov, E. (2016). Universalism, conservation and attitudes toward minority groups. Social Science Research, 58, 68-79.

73. Roccas, S., \& Amit, A. (2011). Group heterogeneity and tolerance: The moderating role of conservation values. Journal of Experimental Social Psychology, 47(5), 898907.

74. Bloom, P. B. N., \& Bagno-Moldavsky, O. (2015). The conditional effect of network diversity and values on tolerance. Political Behavior, 37(3), 623-651.

75. Cieciuch, J., Schwartz, S. H. (2017). Values and human being. In M. van Zomeren \& J. F. Dovidio (Eds.), The Oxford handbook of human essence. Oxford, UK: Oxford University Press.

76. Hofstede, G. (2000). Culture's consequences: Comparing values, behaviors, institutions, and organizations across nations (2nd ed.). Beverly Hills, CA: Sage.

77. Grossberg, S. (1980). How does a brain build a cognitive code? Psychological Review, 87(1), 1-51.

78. Döring, A. K., Schwartz, S. H., Cieciuch, J., Groenen, P. J., Glatzel, V., Harasimczuk, J., ..., \& Milfont, T. L. (2015). Cross-cultural evidence of value structures and priorities in childhood. British Journal of Psychology, 106(4), 675-699.

79. Lee, J. A., Ye, S., Sneddon, J. N., Collins, P. R., \& Daniel, E. (2017). Does the intraindividual structure of values exist in young children? Personality and Individual Differences, 110, 125-130.

80. Cieciuch, J., Davidov, E., \& Algesheimer, R. (2016). The stability and change of value structure and priorities in childhood: A longitudinal study. Social Development, 25(3), 
503-527.

81. Benish-Weisman, M., Daniel, E., \& Knafo-Noam, A. (2017). The relations between values and aggression: A developmental perspective. In S. Roccas \& L. Sagiv (Eds.), Values and behavior: Taking a cross-cultural perspective. Springer.

82. Berzonsky, M. D., Cieciuch, J., Duriez, B., \& Soenens, B. (2011). The how and what of identity formation: Associations between identity styles and value orientations. Personality and Individual Differences, 50(2), 295-299.

83. Uzefovsky, F., Döring, A. K., \& Knafo-Noam, A. (2016). Values in middle childhood: Social and genetic contributions. Social Development, 25(3), 482-502.

84. Knafo, A., \& Spinath, F. M. (2011). Genetic and environmental influences on girls' and boys' gender-typed and gender-neutral values. Developmental Psychology, $47(3), 726-731$.

85. Schermer, J. A., Feather, N. T., Zhu, G., \& Martin, N. G. (2008). Phenotypic, genetic, and environmental properties of the Portrait Values Questionnaire. Twin Research and Human Genetics, 11(5), 531-537.

86. Vukasović, T., \& Bratko, D. (2015). Heritability of personality: A meta-analysis of behavior genetic studies. Psychological Bulletin, 141(4), 769-785.

87. Schönpflug, U. (2001). Intergenerational transmission of values: The role of transmission belts. Journal of Cross-Cultural Psychology, 32(2), 174-185.

88. Knafo, A., \& Schwartz, S. H. (2001). Value socialization in families of Israeli-born and Soviet-born adolescents in Israel. Journal of Cross-Cultural Psychology, 32(2), 213228.

89. Whitbeck, L. B., \& Gecas, V. (1988). Value attributions and value transmission between parents and children. Journal of Marriage and the Family, 829-840. 
90. Grusec, J. E., \& Goodnow, J. J. (1994). Impact of parental discipline methods on the child's internalization of values: A reconceptualization of current points of view. Developmental Psychology, 30(1), 4-19.

91. Knafo, A., \& Schwartz, S. H. (2004). Identity formation and parent-child value congruence in adolescence. British Journal of Developmental Psychology, 22(3), 439458.

92. Knafo, A., \& Schwartz, S. H. (2003). Parenting and adolescents' accuracy in perceiving parental values. Child Development, 74(2), 595-611.

93. McPherson, M., Smith-Lovin, L., \& Cook, J. M. (2001). Birds of a feather: Homophily in social networks. Annual Review of Sociology, 27, 415-444.

94. Bardi, A., \& Goodwin, R. (2011). The dual route to value change: Individual processes and cultural moderators. Journal of Cross-Cultural Psychology, 42(2), 271-287.

95. Schwartz, S. H. (2005). Robustness and fruitfulness of a theory of universals in individual human values. In A. Tamayo \& J. B. Porto (Eds.), Valores $e$ comportamento nas organizacións [Values and behavior in organization] (pp. 5695). Petropolis, Brazil: Vozes.

96. Milfont, T. L., Milojev, P., \& Sibley, C. G. (2016). Values stability and change in adulthood: A 3-year longitudinal study of rank-order stability and mean-level differences. Personality and Social Psychology Bulletin, 42(5), 572-588.

97. Lönnqvist, J. E., Jasinskaja-Lahti, I., \& Verkasalo, M. (2011). Personal values before and after migration: A longitudinal case study on value change in Ingrian-Finnish migrants. Social Psychological and Personality Science, 2(6), 584-591.

98. Rokeach, M. (1975). Long-term value changes initiated by computer feedback. Journal of Personality and Social Psychology, 32(3), 467-476. 
99. Roccas, S., Sagiv, L., \& Navon, M. (forthcoming). From theory to measurement and back: Methodological issues in studying personal values. In S. Roccas \& L. Sagiv (Eds.), Values and behavior: Taking a cross-cultural perspective. Springer.

100. Bardi, A., Lee, J. A., Hofmann-Towfigh, N., \& Soutar, G. (2009). The structure of intraindividual value change. Journal of Personality and Social Psychology, 97(5), 913929.

101. Cieciuch, J., Davidov, E., Vecchione, M., Beierlein, C., \& Schwartz, S. H. (2014). The cross-national invariance properties of a new scale to measure 19 basic human values: A test across eight countries. Journal of Cross-Cultural Psychology, 45, 764-779.

102. Kluckhohn, F. R., \& Strodtbeck, F. L. (1961). Variations in value orientations. Evanston, IL: Row, Peterson.

103. Hofstede, G. (1980). Culture's consequences: International differences in workrelated values. Beverly Hills, CA: Sage.

104. Inkeles, A., \& Levinson, D. J. (1969). National character: The study of modal personality and sociocultural systems. The Handbook of Social Psychology, 4, 418506.

105. Hofstede, G., \& Bond, M. H. (1988). The Confucius connection: From cultural roots to economic growth. Organizational dynamics, 16(4), 5-21.

106. Hofstede, G. J., \& Minkov, M. (2010). Cultures and organizations: Software of the mind (3rd ed.). New York, NY: McGraw-Hill.

107. Hofstede, G. (2011). Dimensionalizing cultures: The Hofstede model in context. Online Readings in Psychology and Culture, 2(1).

108. Schwartz, S. H. (2014). National culture as value orientations: Consequences of value differences and cultural distance. Handbook of the Economics of Art and 
Culture, 2, 547-586.

109. Inglehart, R. (1997). Modernization and postmodernization: Cultural, economic, and political change in 43 societies. Chichester, UK: Princeton University Press.

110. Inglehart, R. (2006). Mapping global values. Comparative Sociology, 5(2), 115-136.

111. Inglehart, R., \& Welzel, C. (2005). Modernization, cultural Change, and democracy: The human development sequence. Cambridge, UK: Cambridge University Press.

112. House, R., Javidan, M., \& Dorfman, P. (2001). Project GLOBE: An introduction. Applied Psychology: An International Review, 50, 489-505.

113. Smith, P. B., Dugan, S., \& Trompenaars, F. (1996). National culture and the values of organizational employees a dimensional analysis across 43 nations. Journal of CrossCultural Psychology, 27(2), 231-264.

114. Hofstede, G. (2001). Culture's recent consequences: Using dimension scores in theory and research. International Journal of Cross Cultural Management, 1(1), 11-17.

115. Inglehart, R. (2015). The silent revolution: Changing values and political styles among Western publics. Princeton, NJ: Princeton University Press.

116. Sagiv, L., Schwartz, S. H., Arieli, S. (2011). Personal values, national culture and organizations: Insights applying the Schwartz value framework. In N. N. Ashkanasy, C. Wilderom, \& M. F. Peterson (Eds.), The handbook of organizational culture and climate ( $2^{\text {nd }}$ ed., pp. 515-537). Newbury Park, CA: Sage. 
Table 1.

Value definitions in Schwartz Value Theory (adapted from Cieciuch et al. ${ }^{101}$ )

\begin{tabular}{|c|c|c|}
\hline $\begin{array}{l}10 \text { basic } \\
\text { values }\end{array}$ & $\begin{array}{l}\text { Definitions of } 10 \text { basic values } \\
\text { (in parentheses, value items) }\end{array}$ & 19 values in the refined values theory ${ }^{21}$ \\
\hline Self-Direction & $\begin{array}{l}\text { Independent thought and action- } \\
\text { choosing, creating, and exploring } \\
\text { (freedom, creativity, independent, } \\
\text { choosing my own goals, curiosity) }\end{array}$ & $\begin{array}{l}\text { Self-Direction-Thought (the freedom } \\
\text { to cultivate one's own ideas and } \\
\text { abilities) } \\
\text { Self-Direction-Action (the freedom to } \\
\text { determine one's own actions) }\end{array}$ \\
\hline Stimulation & $\begin{array}{l}\text { Excitement, novelty, and challenge in } \\
\text { life (exciting life, varied life, daring) }\end{array}$ & $\underline{\text { Stimulation-Definition unchanged }}$ \\
\hline Hedonism & $\begin{array}{l}\text { Pleasure and sensuous gratification for } \\
\text { oneself (pleasure, enjoying life, self- } \\
\text { indulgent) }\end{array}$ & $\underline{\text { Hedonism}}$-Definition unchanged \\
\hline Achievement & $\begin{array}{l}\text { Personal success through } \\
\text { demonstrating competence according } \\
\text { to social standards (ambitious, capable, } \\
\text { influential, successful) }\end{array}$ & Achievement-Definition unchanged \\
\hline
\end{tabular}

\begin{tabular}{|c|c|c|}
\hline \multirow{3}{*}{ Power } & \multirow{3}{*}{$\begin{array}{l}\text { Social status and prestige, control or } \\
\text { dominance over people and resources } \\
\text { (social power, wealth, authority) }\end{array}$} & $\begin{array}{l}\text { Power-Dominance (power through } \\
\text { exercising control over people) }\end{array}$ \\
\hline & & $\begin{array}{l}\text { Power-Resources (power through } \\
\text { control of material and social resources) }\end{array}$ \\
\hline & & $\begin{array}{l}\text { Face (security and power through } \\
\text { maintaining one's public image and } \\
\text { avoiding humiliation) }\end{array}$ \\
\hline \multirow[b]{2}{*}{ Security } & \multirow{2}{*}{$\begin{array}{l}\text { Safety, harmony and stability of } \\
\text { society, relationships, and self (social } \\
\text { order, national security, family } \\
\text { security, reciprocation of favors, clean) }\end{array}$} & $\frac{\text { Security-Personal (safety in one's }}{\text { immediate environment) }}$ \\
\hline & & $\begin{array}{l}\text { Security-Societal (safety and stability } \\
\text { in the wider society) }\end{array}$ \\
\hline \multirow[b]{2}{*}{ Conformity } & \multirow{2}{*}{$\begin{array}{l}\text { The restraint of actions, inclinations, } \\
\text { and impulses that are likely to upset or } \\
\text { harm others and violate social } \\
\text { expectations or norms (politeness, } \\
\text { self-discipline, respect for elders, } \\
\text { obedient) }\end{array}$} & $\begin{array}{l}\text { Conformity-Rules (compliance with } \\
\text { rules, laws, and formal obligations) }\end{array}$ \\
\hline & & $\begin{array}{l}\text { Conformity-Interpersonal (avoidance } \\
\text { of upsetting or harming other people) }\end{array}$ \\
\hline Tradition & $\begin{array}{l}\text { Respect, commitment and acceptance } \\
\text { of the customs and ideas that }\end{array}$ & $\begin{array}{l}\text { Tradition (maintaining and preserving } \\
\text { cultural, family or religious traditions) }\end{array}$ \\
\hline
\end{tabular}


traditional culture or religion provides Humility (recognizing one's

(respect for tradition, modest, humble, insignificance in the larger scheme of accepting my portion in life, devout) things)

\begin{tabular}{lll}
\hline Benevolence & $\begin{array}{l}\text { Preservation and enhancement of the } \\
\text { welfare of people with whom one is in } \\
\text { frequent personal contact (loyal, } \\
\text { responsible, honest, helpful, forgiving) }\end{array}$ & $\begin{array}{l}\text { Benevolence-Dependability (being a } \\
\text { reliable and trustworthy member of the } \\
\text { ingroup) } \\
\text { Benevolence-Caring (commitment to } \\
\text { the welfare of ingroup members) }\end{array}$ \\
\hline $\begin{array}{l}\text { Understanding, appreciation, tolerance } \\
\text { and protection for the welfare of all } \\
\text { people and of nature (equality, unity } \\
\text { with nature, wisdom, world of peace, } \\
\text { world of beauty, social justice, } \\
\text { broadminded, protecting the } \\
\text { environment) }\end{array}$ & $\begin{array}{l}\text { Universalism-Concern (commitment to } \\
\text { equality, justice and protection for all } \\
\text { people) }\end{array}$ \\
\hline & $\begin{array}{l}\text { Universalism-Nature (preservation of } \\
\text { the natural environment) } \\
\text { Universalism-Tolerance (acceptance }\end{array}$ \\
\hline
\end{tabular}


Figure 1. The Content and Structure of Human Values. From Davidov, Schmidt, and Schwartz ${ }^{23}$, p.425.

Box 1. Cultural-Level Values: Values of Social Collectives. 